\title{
1. Distributional effects of environmental policy: introduction
}

Nick Johnstone and Ysé Serret

\section{INTRODUCTION}

The present volume is concerned with the distributional impacts associated with the introduction of environmental policies. The book focuses on distributional impacts according to economic status, which is admittedly only one vector by which to assess the distributional questions of a policy. Other possible criteria could include ethnicity, age, geographical or temporal distribution. Each perspective raises complex issues dealt with in a specific literature and can be the subject of a further study by itself. Given the richness of the topic addressed, the intention in the present volume is to centre the approach on distributional issues across one criterion in order to further develop the analysis and review the empirical literature. ${ }^{1}$

The basic unit of analysis applied in the chapters that follow is the household, with a focus on their relative wealth. However, different criteria can be applied as 'proxies' for wealth, such as household current income or lifetime income, household expenditures or expanded notions of wealth. Current annual income has generally been used as a proxy for households' wealth but such a measure is flawed because of its inability to reflect differences in household assets, life-cycle income effects, and other factors. However, while imperfect, it is a measure which is widely available. Where possible, other measures are sometimes used in the empirical studies discussed.

Concern with the distributional impacts of environmental policy according to socio-economic status arises in part out of a widespread fear that such measures can be regressive. This comes from two general perceptions (or perhaps misperceptions): poorer households pay disproportionately more of the financial costs associated with the introduction of environmental policies; and richer households receive disproportionately more of the benefits associated with improved environmental quality. Both of these assertions are controversial and the evidence about their validity is discussed in the chapters that follow. However, what is clear is that environmental policies have the potential to raise significant distributional 
concerns and, as policies become increasingly stringent, these concerns are likely to become more acute.

The book intends to widen the scope of previous analysis of the distributional effects of environmental policies in a number of ways, in particular by:

- Bringing together key aspects necessary better to understand and take into account distributional effects of environmental policy: theoretical analysis, empirical evidence and policy implications.

- Addressing concerns related to both the distribution of environmental quality and the financial effects of environmental policies.

- Adopting a comprehensive approach when looking at the distribution of environmental quality (environmental 'bads' and 'goods').

- Adopting a wide perspective when considering the distribution of financial effects of environmental policy by looking at the effects of different policy instruments, and not just economic instruments.

- Seeking to assess both the direct and indirect compliance costs, as well as taking into account effects arising through related markets (for example, public finance, labour markets, real estate markets).

- Adopting a wide geographical perspective when reviewing the empirical literature, in an effort to mitigate the strong geographical bias in favour of the United States, in particular with respect to the assessment of disparities in the distribution of exposure to environmental risks (for example, hazardous waste sites, toxic releases).

- Developing theoretically founded policy implications for the design and implementation of environmental policy, drawing in particular from the experience of OECD countries in addressing distributional concerns.

This introductory chapter will seek to contextualise the conceptual and empirical discussions in the chapters that follow by discussing some of the broad themes which run through the book, as well as some of the issues which underpin the evidence presented. First and foremost, discussions of distributional concerns cannot be divorced from the notions of 'fairness' which can underpin environmental policy (Section 2). Secondly, it is important to examine the relationship between issues of social equity and economic efficiency (Section 3), even though they are often treated separately in the policy assessment exercise. Thirdly, it is essential to have a clear understanding of the various channels through which the distributional effects of environmental policies can arise, not least because an analysis that focuses on the more evident direct effects can be quite misleading (Section 4). Fourthly, a closely related issue is the choice of policy instruments. The means by which - and the extent to which - distributional effects can arise 
from measures of equal stringency is affected by the characteristics of the policy measure introduced (Section 5). The chapter concludes (Section 6), with a brief overview of the coverage of the book.

\section{DISTRIBUTIONAL IMPACTS AND NOTIONS OF FAIRNESS IN ENVIRONMENTAL POLICY}

It is important to bear in mind the various objectives that can lie behind the widespread view that distributional issues need to be taken into account when introducing and assessing environmental policies. Since the overall distributional impacts of policies are reflected in terms of both financial effects and environmental effects, these cannot be examined in isolation. For public goods it is - almost by definition - impossible to ensure that the beneficiaries of a given policy are the same as those who bear the cost. ${ }^{2}$ Even for local public goods it is rarely possible to restrict the cost implications of a particular environmental policy to its beneficiaries, and it is even more difficult to do so in a manner which reflects actual benefits received.

Thus, assuming that financial costs are borne more or less in proportion with levels of income, distributional concerns are likely to be perceived as less acute if the recipients of the environmental benefits live primarily in lower-income neighbourhoods rather than higher-income neighbourhoods. This is particularly important when there are significant differences in the incidence (in terms of affected populations) of environmental and financial impacts. Thus, it is the relationship between the two which will determine whether or not a given policy is perceived to be 'fair'.

With respect to the specific distribution of environmental quality, some conceptions of 'fairness' generally discussed in the literature to assess the distribution of environmental impacts include: ${ }^{3}$

- Equality of exposure to pollution or access to environmental amenities - for example, all households have the same level of exposure or access.

- Equality of environmental risk - for example, all households face the same level of risk, taking into account physiological and other differences.

- Progressive inequality - for example, systematically using environmental policy as a redistributional mechanism to favour poorer households.

- Procedural fairness - for example, ensuring that all households have the opportunity to express their environmental preferences effectively in the political sphere (such as through public hearings). 
- Protection of 'basic' environmental needs - for example, ensuring that all households have access to a minimum level of environmental quality.

- Situational fairness - for example, ensuring that households continue to enjoy the level of environmental quality to which they have become accustomed (such as when their house was purchased).

- Preference-based notion of equity - in this approach a fair distribution may be one in which levels of environmental quality differ according to differences in demand for environmental quality.

Some of these notions are just elaborations upon one another. For instance, the distinction between equality of exposure and equality of risk is essentially one of measurement. The latter is a refinement on the former, entailing greater monitoring costs. However, the underlying motivation is likely to be similar. In other cases they are potentially complementary. For instance, a belief in the need for procedural fairness and preference-based notions of equity provides alternative means for the expression of demand. In the absence of market or policy failures, one or the other should be redundant.

However, the different principles may also represent different fundamental conceptions of fairness. For instance, the apparent regressivity of a particular policy will depend very much on whether a preference-based notion of equity or a physical risk or exposure notion of equity is adopted. As noted by Pearce (Chapter 2), depending upon the income elasticity of demand for environmental quality, a measure which appears to be regressive in terms of exposure levels may in fact be progressive when a preference-based notion of equity is applied. Thus, while some - but by no means all - studies (for example, Anderton et al., 1994a and 1994b; Brooks and Sethi, 1997; Millimet and Slottje, 2000; Kahn, 2001) indicate that pollution concentration levels are correlated with income, whether or not such a distribution is regressive according to preference-based notions would depend upon demand for environmental quality, and the evidence in this area is very limited (see for example, Hökby and Söderqvist, 2002; and Carson et al., 1995).

Thus, it is important to recognise these differences when trying to identify a government's objective with respect to a particular measure which seeks to redress some perceived distributional imbalance in environmental quality. For instance, policies which restrict the siting of hazardous waste facilities in neighbourhoods with high levels of poverty are more likely to be driven by an underlying belief in the need to protect access to a basic level of environmental quality for all households, than by a belief in preference-based notions of equity. ${ }^{4}$ Indeed, the intention of such a policy may 
well be to override the revealed preferences of the affected community, a point which is taken up by Pearce (Chapter 2) as well as in the concluding chapter.

With respect to financial impacts, the issue is not significantly different from the effects of any public policy. Any policy will result in costs that are different across socio-economic groups depending upon their expenditure patterns, behavioural responses, employment opportunities and so on. Indeed, as emphasised by Kriström (Chapter 3), the main objective of all environmental policies is to change consumption and production patterns. As such, they will have, by their very nature, distributional impacts on households.

Whether or not such differences in impacts are 'fair' needs to be understood in the broader overall context of government policy with respect to the distribution of wealth. If it is assumed, as seems reasonable in the majority of cases, that the existing distribution of wealth in a given society prior to the introduction of a particular policy is considered not to be such as to necessitate additional redistribution policies above and beyond those which are already in place to meet these social objectives (that is, progressive income taxation, social welfare systems and so on), then the key issue is whether or not the distributional effects of the introduction of an additional policy (environmental or other) are 'marginal'.

However, as noted in Kriström (Chapter 3), even determining whether or not the effects are marginal depends crucially upon the 'proxy' for wealth used, such as household current income or lifetime income, household expenditures or expanded notions of wealth. Each has its own limits when looking at distributional issues. The empirical literature suggests that the definition retained may affect the results regarding the regressivity of environmental policy. ${ }^{5}$ In short, conclusions about the distributional impacts of environmental policy in financial terms will differ according to the measure of income applied.

In the event that a particular environmental policy (that is, a carbon tax or a new pollution regulation) is thought to have non-trivial regressive impacts, then, for the sake of social justice, it is important to mitigate these impacts. However, this may not necessarily be done within the framework of the environmental policy itself. As discussed in the concluding chapter of this volume, it may be neither economically efficient nor environmentally effective to modify an environmental policy in order to meet social objectives. Indeed, modifications to the policy itself are unlikely to be the optimal means for addressing the distributional concerns.

Thus, in theory, environmental policy should not generally be the tool for addressing distributional issues, since there are other more suitable 
mechanisms. However, for political reasons it may be necessary to address the distribution of costs within the context of the environmental policy itself. For instance, the proposed $\mathrm{BtU} \operatorname{tax}^{6}$ in the United States and the petrol duty escalator in the United Kingdom were rescinded or reformed in part for distributional reasons. The introduction of countervailing policies with progressive impacts may not suffice to overcome such resistance, and the environmental policy will continue to be viewed as 'unfair'.

As such, the concept of fairness applied can have fundamental implications for the nature of interventions undertaken by public authorities, and on whether or not any intervention should be undertaken at all. Since the principles applied are rarely articulated at the time of introduction of a particular policy, this can lead to considerable confusion. Indeed, there is a strain in economics which cites the plethora and conflicting notions of fairness as reason enough to undermine it as a decision-making criterion (Kaplow and Shavell, 2002). While an extreme view, it does highlight the need to clarify the ultimate policy objective underpinning specific measures which are purported to address distributional concerns.

\section{THE RELATIONSHIP BETWEEN SOCIAL EQUITY AND ECONOMIC EFFICIENCY}

Equity is, of course, only one criterion for assessing environmental policy. Other criteria set out in the OECD report on Evaluating Economic Instruments for Environmental Policy (OECD, 1997) include environmental effectiveness, economic efficiency, administration and compliance costs, public finance, dynamic effects and innovation, soft effects, such as those arising from the use of instruments on attitude and awareness, and other wider economic effects.

The tension which can exist between social equity and economic efficiency objectives is particularly important, and the issue is not fully resolved in the literature. Indeed, the debate is rarely engaged in the economic literature due to the use of 'Pareto Superiority' as the predominant means of policy evaluation in economics. Any policy or project in which everyone gains passes the test, and one in which everyone loses fails the test. However, as Kriström (Chapter 3) points out, almost all policies generate 'losers' and 'winners', and imposing the constraint that all must benefit from the introduction of each and every policy can only be an excuse for political paralysis.

In order to make the test of practical policy relevance, a number of conceptual refinements have been developed, perhaps most famously in the form of the Kaldor-Hicks criterion which states that a policy is 'welfareimproving' when the sum of benefits exceeds the sum of costs - that is, even 
if there are 'losers' from its introduction, a policy is socially beneficial if the winners can compensate the losers (see Johansson, 1993, for a discussion). Whether or not the compensation is actually paid is incidental to whether or not the Kaldor-Hicks criterion is in fact met. If it is hypothetically possible for the winners to compensate the losers such that both groups are net beneficiaries, that is sufficient.

Therefore, an environmental policy which brings considerable benefits to a small minority, but imposes lower overall costs on a large majority will satisfy the Kaldor-Hicks criterion since overall social welfare will have increased. In many cases this may be appropriate. For instance, if the initial distribution is 'optimal' and if the distributional effects of a given policy are marginal, it can hardly be administratively efficient to seek to ensure that such effects are addressed case by case with the introduction of each and every policy. The introduction of an advanced disposal fee on lead-acid batteries to cover disposal costs and environmental externalities will have distributional implications (because both the costs and the benefits are borne unequally), but these are not likely to be important enough to warrant the introduction of compensating measures.

However, there are cases in which the introduction of compensating measures is clearly required in order to ensure that the policy is acceptable. Even if the same population bears the financial costs and gains the environmental benefits, the distribution may be such as to make the measure politically infeasible or socially unacceptable. For instance, many OECD governments which have introduced environmentally-motivated energy taxes have simultaneously introduced compensating measures in order to reduce their regressivity. Since the effects were non-trivial, it was felt that such compensating measures needed to be part of the same 'policy package'.

In some cases, these 'compensating measures' are introduced through general reforms of tax policy. For instance, the revenue generated by an environment-related tax can be used to reduce tax rates for lower-income households, which would result in a more progressive fiscal policy in general. In other cases, it may be more directly targeted at those households which are most affected by the environmental policy - that is, lower-income rural households in the face of petrol taxes. The effects of such compensating measures on economic efficiency will be marginal as long as the incentive effects of the environmental policy remain untouched. ${ }^{7}$

In still other cases, governments may actually seek to marry improved social equity with economic efficiency. For instance, it has often been argued that lower-income households faced particular market failures (split incentives, information failures, credit market failures and so on) which prevented them from responding to environment-related residential energy taxes, and as a consequence complementary measures are needed to 
address such failures for distributional reasons (for an early discussion of these issues, see Brechling et al., 1991). Governments have sought to introduce compensating measures which not only address equity concerns but also increase economic efficiency by addressing such failures or barriers. This is discussed in the concluding chapter.

In other cases it may be possible to deal with the distributional impacts directly within the implementation of the policy instrument itself. For instance, it is frequently argued that one of the great advantages of tradable permits over other policy measures is the apparent separability of equity and efficiency objectives through the policy itself, via the initial allocation of permits. In this case, the pursuit of equity will not undermine efficiency objectives. Equity can be addressed in the initial permit allocation, and this will have no bearing on efficiency since efficiency is not affected by the way permits are allocated initially.

However, under certain circumstances this apparent separability breaks down. For instance, if the value of the permits has significant impacts on income levels and income elasticity of demand for the goods is non-linear then the allocation of permits will affect the aggregate level of demand for the environmental good. Only one specific distribution of permits will ensure that all agents have marginal costs equal to marginal benefits. ${ }^{8}$

In addition, for political reasons (including distributional concerns) many countries are actively considering using allocation mechanisms involving 'updating' in which current production and/or emission levels affect future permit allocations. ${ }^{9}$ While this will likely come at a welfare cost, Böhringer and Lange (2005) point out that the magnitude of such costs will depend crucially upon whether or not the emissions trading scheme is 'open' or not. If the regulatory agency cannot take the overall allocation as given, different allocation rules will have different distributional and welfare implications.

Another area in which equity issues have been addressed directly within the policy measure itself is in the provision of environment-related public services where price discrimination on the basis of consumption levels is possible. For instance, through the use of escalating tariffs it is possible to reduce the regressivity associated with the imposition of user fees in the provision of water and sanitation services. While this is likely to have some impact on economic efficiency - particularly if tariffs are very low at low consumption levels - the incentive effects remain largely in place.

Moreover, there can be other 'public' motives to ensure minimum levels of consumption of environment-related public services. For instance, due to possible health externalities it may be economically inefficient to 'price' initial levels of service provision equal to the marginal environmental damages (environmental externalities and resource rents). At excessively 
low levels of consumption, private preferences may not reflect the public good benefits of reduced health externalities associated with higher levels of consumption. ${ }^{10}$ In addition, even in the absence of such externalities there may be a widely-held social perception that basic levels of provision for all households are preconditions for maximising social welfare (see Johnstone et al., 2002a for a discussion).

In summary, the Kaldor-Hicks criterion can be interpreted as a way of allowing for the separation of equity and efficiency. ${ }^{11}$ It can be seen as an argument for removing the burden of tackling distributional matters from the sphere of environmental policy. This may not, however, be politically feasible since - as noted above - the implementation of environmental policies is often constrained in practice by concerns over distributional matters. As such, if the effects on distribution are not trivial, then the mere 'possibility' of compensating poorer households may not suffice to justify a given policy intervention. Some compensating measure may need to be applied.

In addition to the potential impacts of environmental policies on the distribution of financial and environmental costs and benefits, it is also possible that the initial distribution of income will affect aggregate levels of demand for environmental quality for society as a whole (rather than for a given group of individuals). Moreover, it may also have an effect on the likelihood of this demand being effective, whether through public interventions or collective action.

On the one hand, if the income elasticity of demand for environmental quality is non-linear, then the initial distribution of income will affect aggregate demand. If, for instance, income elasticity of demand is convex, a more unequal distribution of income will lead to greater demand for environmental quality. Analogously, a concave income elasticity of the demand curve means that demand will be maximised at more equal distributions of income (see Boyce, 2003). As noted above, the evidence with respect to the income elasticity of demand for environmental quality remains an area requiring further empirical research (see Pearce in Chapter 2). Preliminary assessments of potential non-linearities in this relationship were undertaken by Kriström and Riera (1996), and they were unable to reject the possibility that the income-environmental quality relationship is non-linear.

On the other hand, there is a rich vein of literature which has examined the role of income distribution in encouraging or discouraging collective action to protect common property resources such as fisheries and pastureland. Olson (1965) argued that unequal distribution of income was likely to lead to greater conservation of common property resources for the simple reason that it was more likely that a small number of agents would be willing to bear a disproportionate share of the total costs of conservation in order to reap the benefits of conservation of the resource. 
However, more recent literature is more ambiguous, finding that under plausible conditions a more equal distribution of wealth will lead to greater protection of common property environmental resources (Baland and Platteau, 1997; Dayton-Johnson and Bardhan, 2002). Drawing upon the insights of Becker (1983), Hamilton (Chapter 7) discusses issues of collective action in relation to the siting of hazardous waste treatment and disposal facilities.

\section{CHANNELS THROUGH WHICH DISTRIBUTIONAL EFFECTS OF ENVIRONMENTAL POLICIES CAN ARISE}

The most evident (and often most important) channel through which the financial impacts of an environmental policy can arise relate to the effect of a given policy on the price of a good or service which is directly targeted by the policy measure. For example, the distributional effects of an environmentally-motivated fuel tax will depend upon how important fuel consumption is in the total basket of expenditures for low-income and high-income households. Similarly, the distributional effects of an energy efficiency standard for appliances will depend on the consumption and use of such appliances by households in different income brackets.

Indeed, the vast majority of existing empirical studies focus almost exclusively on the direct financial incidence of individual environmental policies. (Kriström, in Chapter 3, provides a review of recent studies.) In general, and for a wide variety of policy measures, such analyses reveal that impacts can be regressive. For instance, this is certainly true of carbon taxes. (See Brännlund and Nordström, 2004; and Cornwell and Creedy, 1997, for examples from Sweden and Australia respectively.)

However, this can provide misleading indications of the degree of progressivity or regressivity of the impacts of the policy. For instance, differences in behavioural responses of different income groups in the face of the introduction of a policy can affect the distributional impacts of the policy. On the one hand, substitution possibilities may differ markedly between different income brackets. On the other hand, price elasticities will differ in a relatively predictable manner depending upon differences in the share of affected goods and services in total expenditures across income levels. Ignoring such differences would overestimate the financial impact of the policy on low-income households relative to high-income households. In other cases, differences in behavioural responses may accentuate the distributional impacts.

West and Williams (2002) provide recent evidence on the implications of 
gasoline taxes on different income groups in the United States. They find that the price elasticity of the low-income quintile is approximately twice that of the high-income group. Sipes and Mendelsohn (2001) reach a similar conclusion. However, in a study of carbon taxes in Australia, Cornwell and Creedy (1997) find that low-income households have lower price elasticities. Thus, it is important to examine this on a case-by-case basis. For instance, in some markets substitution possibilities may be greater for high-income households, increasing their sensitivity to price changes. A thorough understanding of demand patterns across different socio-economic groups is essential.

In addition, it is important to take into account the indirect effects of environmental policies. Unless a given environmental policy only affects a final household good or service, there will be pass-through effects on downstream goods and services. Thus, a general energy tax (rather than a tax on residential energy use) will affect the costs of all goods and services in relation to their energy use. ${ }^{12}$ Similarly, a technology-based standard to reduce biological oxygen demand in the production of pulp will affect the cost of stationery, books, newspapers and so on. (See Kriström, Chapter 3, for a discussion.)

In general, taking into account such input-output linkages appears to diminish the apparent strong regressivity (or progressivity) of at least some policies. The reason is intuitive and can be illustrated with the example of an energy tax. If the direct effects are significantly regressive due to the high importance of energy in the consumption basket of low-income households relative to high-income households, such effects will be mitigated to the extent that all other goods consumed which have energy inputs are consumed proportionately less in a relative sense by lower-income households.

In addition to the direct and indirect markets for the goods and services themselves, it is also important to take into account the effects produced through impacts on other markets and other public policy spheres. One of the most important issues relates to the impacts of a given environmental policy on the fiscal stance of the public authority. Some policy measures may have significant implications for public expenditures (for example, subsidies for investment in nature conservation or pollution abatement). Depending upon how the revenue is generated to finance such expenditures, impacts may be very different. Even direct regulations may necessitate significant expenditures on monitoring and enforcement.

However, some other measures may be net generators of government revenue. For instance, auctioned tradable permits or environment-related taxes can generate revenues in excess of any costs associated with policy implementation. In such cases, the means of revenue recycling can have 
significant implications for the distributional effects of a policy. Thus, recycling via reduced income taxes, corporate taxes or sales taxes will have a very different incidence for the distribution of impacts. This is an issue giving rise to lively discussion in the literature and some of the results are reviewed in Kriström (Chapter 3). Indeed, holding other factors constant, the means of recycling adopted may affect whether a policy is regressive or progressive. (See the aforementioned study by West and Williams, 2002; as well as Parry, 2004.)

Environmental policies affect different socio-economic groups not only as consumers and taxpayers, but also as wage-earners and shareholders. In some cases, the effects of environmental policies on employment markets, particularly in sectors directly affected by an environmental policy, may be more important than the distributional effects of policies in affected consumption markets (see OECD, 2003). Obvious examples relate to natural resource-based sectors. Because of the relative isolation and skill-specificity of employment opportunities in sectors such as forestry, mining and fisheries, it is sometimes argued that environmental policies in such sectors may have particularly important impacts on earning opportunities for those affected.

And, finally, environmental policies can have distributional implications through other markets in which the associated environmental improvement is, at least partly, embedded. In particular, for local public goods ('Tiebout goods'), the financial effects of environmental policies will not only be reflected in the cost of the policy measure per se, but also in the impact that the change in environmental quality has on other markets (see Pearce, Chapter 2 in the present volume). For instance, real estate prices are likely to be affected positively by the siting of an urban park in the neighbourhood and negatively by the siting of a disamenity such as a landfill site. (See Hamilton, Chapter 7, for a discussion of the latter case.)

It is important to take these impacts into account if a full assessment of the distributional impacts of a policy are to be determined. Taking the example of the urban park siting, the financial effect will be positive for local home-owners, as will the environmental benefits. However, it will be negative for tenants, and the non-monetised benefits in terms of access to the park may be of less value than any eventual rent increase. In such cases, there will be a natural 'sorting' in the affected markets with long-run impacts being very different from any short-run impacts (see Tiebout, 1956, for the original discussion). ${ }^{13}$ 


\section{THE EFFECTS OF POLICY INSTRUMENT CHOICE ON DISTRIBUTIONAL IMPACTS}

When examining the distributional issues related to the use of environmental policies, the literature generally focuses on the possible regressive impacts of economic instruments, especially taxes. In general it is felt that they are likely to have particularly regressive effects. In some sense, there is good reason - at least at first sight - for such an assumption. In the case of economic instruments (whether environment-related taxes or auctioned tradable permits), the rent associated with the use of the environment is received by the government.

However, in the case of direct regulation (whether technology-based standards or performance-based standards), the rents associated with the residual pollutants which continue to be emitted after specified abatement is undertaken are granted to the emitters themselves. In effect, in a partial equilibrium framework, the total costs of compliance under economic instruments have two elements (abatement costs and tax payments/permit purchases), while under direct regulation only the costs of abatement arise. This may accentuate the distributional impacts associated with the achievement of a given environmental target.

As has been noted above, this widespread belief in the greater potential for there being regressive impacts from the introduction of an economic instrument may be due in part to the focus on the 'direct' effects of the two classes of instruments. In particular, once the potential for revenue recycling is included in the analysis, it is much less clear that impacts are likely to be more regressive under the application of economic instruments. With the use of environment-related taxes or auctioned tradable permits the 'rents' which are granted to emitters under direct regulation can be used to offset any potential negative distributional impacts. Analogously, available evidence underlines how significantly the way of allocating permits affects the distributional impacts of tradable permits (auctioned versus grandfathered) (see Markandya, 1998; Cramton and Kerr, 1999; Dinan and Rogers, 2002; ${ }^{14}$ Parry, 2004 ${ }^{15}$ ).

Thus, whether or not a policy is regressive depends very much on the means of recycling applied. For instance, recycling via reduced income taxes will have very different effects from recycling via reduced value-added taxes. Indeed, the means of recycling can convert a policy from being regressive to being progressive. In a study of $\mathrm{SO}_{2}$, carbon and $\mathrm{NO}_{\mathrm{x}}$ policy, Parry (2004) finds that emissions taxes go from being progressive under 'proportional recycling' (that is, in proportion to ex ante tax burdens) to strongly progressive under 'lump-sum' recycling (that is, equal rebates to all households). (See Symons et al., 1994; Metcalf, 1999; and Bovenberg and 
Goulder, 2002 for studies on the importance of the means of recycling assumed.)

The importance of the overall fiscal policy regime is also clearly evident with the use of environmentally-motivated subsidies. In this case, the distributional impacts will arise from the degree of regressivity or progressivity of the tax system used to raise the finance required to pay for such programmes. Interestingly, however, many subsidy programmes have been used to address both distributional and environmental objectives simultaneously. Examples include energy conservation subsidies or investment programmes to promote renewable energy. In the first case, at least, these policies are targeted directly at lower-income households. Thus, the subsidy is being used to address two objectives simultaneously - that is, internalisation of the environmental externality and distributional objectives. This is usually justified by the existence of significant market failures or barriers which increase the cost to low-income households and reduce their responsiveness to particular policy incentives. The efficiency of using subsidies in this way is a point taken up in the concluding chapter.

Another possible reason why there is a widespread belief that economic instruments have the potential to be more regressive than direct regulation is the transparency of their effects. Even if a market-based instrument and a direct regulation are targeted at the same environmental objective, the cost (and thus distributional) effects of the former may be more apparent. Taking the example of energy efficiency, it is possible to achieve given targets with a tax (encouraging the purchase and design of more efficient appliances) or through performance standards, mandating minimum levels of energy efficiency. The distributional effect of the former is quite transparent.

However, the effects of the latter are much less evident. As Sutherland (Chapter 5) points out, if low-income households have higher revealed discount rates than high-income households, ${ }^{16}$ and if more energy-efficient appliances have higher capital/operating cost ratios than they would normally purchase, the effect of energy performance standards on appliances will be to override the temporal preferences of low-income households, restricting their options in the market with adverse effects on welfare. ${ }^{17}$ More generally, when the indirect effects of both economic instruments and direct regulations on manufacturing and other sectors are taken into account, there is no reason to expect that the effects of the latter will be less regressive. (See Robison, 1985 for an early example of the application of input-output analysis to evaluating the distributional effects of direct forms of regulation.)

While infrequently assessed, liability for environmental damages can also have distributional implications. (See Ringquist, 1998; and Kanner, 2004, 
for discussions.) The distributional impacts of legal liability regimes are likely to vary widely depending upon the means by which damages are compensated in cases in which a firm (or other agent) is held responsible for adverse environmental impacts. In particular, the distributional impacts will not be the same whether damages are compensated on the basis of lost earnings or production losses, or according to fixed criteria set regardless of households economic status. What principles are applied varies widely across OECD countries, and differences are likely to be particularly important between civil law and common law regimes.

In short, all policy instruments have potential but different distributional impacts. To get a full picture of these effects, both direct and indirect channels through which they can arise are to be considered. Such an analysis tends to be easier to carry out in the case of taxes and auctioned tradable permits where the direct effects on household groups are generally more straightforward. However, even for taxes the case is complicated by the inclusion of indirect impacts, revenue recycling and behavioural adjustments. The fact that the distributional implications of taxes are particularly highlighted is probably due to their greater 'visibility' and should not be construed as an indication of their greater regressivity per se.

\section{STRUCTURE OF THE BOOK}

The first part of the book (Chapters 2 and 3) provides conceptual frameworks for assessing the distribution of environmental impacts and of the financial effects of environmental policies. It draws upon insights from environmental economics, welfare economics, public economics and political philosophy. It reviews the mechanisms through which the benefits and costs of environmental policies affect the individual household, and the reasons why such impacts are likely to be unevenly distributed.

The conceptual frameworks developed build on the framework for assessing the distributional implications of economic instruments used in previous work (OECD, 1994) and elaborate upon it by extending the analysis to include other forms of environmental policies. In addition, while many studies focus on the direct financial incidence of individual policies, this can provide misleading indications of the progressivity or regressivity of the impacts of the policy. As such, the analysis has been extended to include additional channels through which distributional effects arise (for example, indirect effects, differences in behavioural response by household type, the effects of policies on related markets such as real estate and labour markets).

Empirical evidence on the distributional implications of environmental policies is examined in the second part through selected case studies, 
including: ecological tax reforms in Germany (Chapter 4), regulatory approaches to residential energy efficiency (Chapter 5), exposure to noise in the United Kingdom (Chapter 6), and proximity to hazardous waste facilities in OECD countries (Chapter 7).

Chapter 8 examines the policy measures which have been introduced in OECD countries to address these distributional concerns. Building on this experience, the book reviews some of the challenges facing policy-makers as they seek to design environmentally effective and economically efficient environmental policies, while ensuring that social concerns such as distributional effects are simultaneously tackled. On the basis of the review and analysis of these key sets of issues to be addressed, policy implications are drawn.

\section{NOTES}

1. Thus, issues such as temporal inequality arising from distributional effects across generations is not covered. Similarly, distributional effects along racial-ethnic lines are not discussed. However, it must be recognised that there can be strong links between these different characteristics. As such, some of these other elements are addressed in cases where they are particularly strongly related to the distribution of household wealth and income.

2. It is the non-excludability and non-rivalry of consumption of public environmental goods that necessitates public policy interventions.

3. For a recent discussion of the principles of fairness underpinning different environmental policies in the United States, see Hsu (2004). Shoup (1989) provides a useful discussion of issues of fairness in allocation rules for public services such as water and sanitation.

4. Although such a policy is not necessarily inconsistent with a preference-based notion of equity if it is felt that there are market or policy preferences which prevent the expression of such preferences for low-income households.

5. In general, studies indicate that the regressive impacts of taxes are more limited in a lifetime context. For instance, a tax on gasoline appears less regressive than other analyses suggest when taken as a percentage of total consumption expenditures used as a proxy for lifetime income (Poterba, 1991). In a similar way, looking at the distributional effects of a shift in taxes on motor vehicle emissions, Walls and Hanson (1999) conclude that results depend heavily on the measure of income used and that the three vehicle pollution control policies examined are much less regressive when considering lifetime income than on the basis of annual income. Smith (1992) notes however that this conclusion may depend on a number of factors and that, in the case of energy and carbon taxation in the UK, the distinction makes little difference in distributional analysis.

6. In 1993, the Clinton Administration proposed a differential BtU tax on fossil fuels (a broadly-based general tax primarily on oils, gas and coal, based on the British Thermal Units of heat output).

7. Although there will be some loss of efficiency through the blunting of the 'output' effect of the policy - that is, demand for the goods and services affected will be greater than is optimal.

8. See Chichilnisky and Heal (1994) and Shiell (2003). See also McGuire and Aaron (1969) for a general theoretical discussion of the relationship between efficiency and equity in the supply of public goods. 
9. For instance, in the context of the EU Emissions Trading Directive, the German Government's national permit allocation plan allows for ex post correction of allowances in the event of a substantial change in emission or production levels (see Böhringer and Lange, 2005).

10. Note that the importance of this only arises due to the discretionary nature of consumption of the environmental good.

11. The notion of separability refers here to the fact that the pursuit of equity does not undermine the efficiency goal and vice versa.

12. And depending upon substitution possibilities in production.

13. As noted in the concluding chapter below, this 'sorting' effect can have significant implications for the ability of a given policy to address distributional concerns. Efforts to site environmental amenities in lower-income neighbourhoods will ultimately be at least partially self-defeating as real estate prices rise in the face of such improvements. In effect, the government is in danger of 'chasing its own tail', in a futile effort to follow conditions in markets affected by its own policy interventions.

14. Examining the effects of a 15 per cent reduction in US carbon emissions under different allocation mechanisms, Dinan and Rogers (2002) estimate that the lowest-income households would be worse off under grandfathered permits while top-income households would be better off. The low-income households would be better off if, instead, the permits were auctioned with revenues recycled in equal lump-sum rebates for all households.

15. In an assessment of the distributional impacts of tradable emissions permits for carbon, $\mathrm{SO}_{2}$ and $\mathrm{NO}_{\mathrm{x}}$ in the US, Parry (2004) shows that grandfathered emissions permits can have a significant regressive effect as the rent ultimately accrues to shareholders.

16. A point which is supported by the empirical evidence. See Johnstone et al. (2002b) for a review.

17. Fisher (2004) points out that this result may not hold if the supply of appliances is not perfectly competitive.

\section{REFERENCES}

Anderton, D., A. Anderson, J. Oakes, M. Fraser, E. Weber and E. Calabrese (1994a), 'Hazardous Waste Facilities: Environmental Equity Issues in Metropolitan Areas', Evaluation Review, 18(2), 123-40.

Anderton, D., A. Anderson, J. Oakes and M. Fraser (1994b), 'Environmental Equity. The Demographics of Dumping in Dixie', Demography, 31(2), 229-48.

Baland, Jean-Marie and Jean-Philippe Platteau (1997), 'Wealth Inequality and Efficiency in the Commons', Oxford Economic Papers, 49(4), 451-82.

Becker, G. (1983), 'A Theory of Competition among Pressure Groups for Political Influence', Quarterly Journal of Economics, 98, 371-400.

Böhringer, Christoph and Andreas Lange (2005), 'On the Design of Optimal Grandfathering Schemes for Emission Allowances', European Economic Review, 49(8), 2041-55.

Bovenberg, L.L. and L.H. Goulder (2002), 'Addressing Industry-Distributional Concerns in U.S. Climate Change Policy', working paper, Stanford University and Tilburg University. Available at http://weber.ucsd.edu/ carsonvs/papers/ 810.pdf.

Boyce, James K. (2003), 'Inequality and Environmental Protection', University of Massachusetts Amherst, Political Economy Research Institute Working Paper No. 51.

Brännlund, R. and J. Nordström (2004), 'Carbon Tax Simulations Using a Household Demand Model', European Economic Review, 48(1), 211-33. 
Brechling, V., D. Helm and S. Smith (1991), 'Domestic Energy Conservation Environmental Objectives and Market Failures', in Dieter Helm (ed.), Economic Policy towards the Environment, Oxford: Blackwell Publishers.

Brooks, N. and R. Sethi (1997), 'The Distribution of Pollution: Community Characteristics and Exposure to Air Toxics', Journal of Environmental Economics and Management, 32, 233-50.

Carson, R., R. Mitchell, M. Hanemann, R. Kopp, S. Presser and P. Ruud (1995), 'Contingent Valuation and Lost Passive Use Damages from the Exxon Valdez', Discussion Paper 95-02, Department of Economics, University of San Diego.

Chichilnisky, G. and G. Heal (1994), 'Who Should Abate Carbon Emissions? An International Viewpoint', Economic Letters, 44(4), 443-9.

Cornwell, A. and J. Creedy (1997), 'Measuring the Welfare Effects of Tax Changes Using the LES: An Application to a Carbon Tax', Empirical Economics, 22, 589-613.

Cramton, P. and S. Kerr (1999), 'The Distributional Effects of Carbon Regulation: Why Auctioned Carbon Permits are Attractive and Feasible', in Thomas Sterner (ed.), The Market and the Environment, International Studies in Environmental Policy Making, Cheltenham and Northampton, MA: Edward Elgar.

Dayton-Johnson, Jeff and Pranab Bardhan (2002), 'Inequality and Conservation on the Local Commons: A Theoretical Exercise', Economic Journal, Royal Economic Society, 112(481), July, 577-602.

Dinan, Terry M. and Diane Lim Rogers (2002), 'Distributional Effects of Carbon Allowance Trading: How Government Decisions Determine Winners and Losers', National Tax Journal, LV, 199-222.

Fisher, Carolyn (2004), 'Who Pays for Energy Efficiency Standards?', Resources for the Future Discussion Paper 04-11.

Hökby, S. and T. Söderqvist (2002), 'Elasticities of Demand and Willingness to Pay for Environmental Services in Sweden', paper to 11th Annual Conference of the European Association of Environmental and Resource Economists, Southampton.

Hsu, Shi-Ling (2004), 'Fairness versus Efficiency in Environmental Law', Canadian Law and Economics Association Annual Meeting, Toronto, September.

Johansson, P.O. (1993), Cost-Benefit Analysis of Environmental Change, Cambridge: Cambridge University Press.

Johnstone, N. et al. (2002a), 'Environmental and Ethical Dimensions of the Provision of an Environmental Basic Need: Water and Sanitation Services in East Africa', in D.W. Bromley and J. Paavola (eds), Economics, Ethics and Environmental Policy, Oxford: Blackwell.

Johnstone, N., N. Caid and Y. Serret (2002b), 'Decision-making and Environmental Policy Design for Consumer Durables', OECD Monograph ENV/EPOC/ WPNEP(2002)7/FINAL.

Kahn, M. (2001), 'The Beneficiaries of Clean Air Act Regulation', Regulation, Spring, 34-8.

Kanner, Allan (2004), 'Equity in Toxic Tort Litigation: Unjust Enrichment and the Poor', Law and Policy, 26(2), 209-30.

Kaplow, Louis and Stephen Shavell (2002), Fairness versus Welfare, Cambridge, MA: Harvard University Press.

Kriström, Bengt and Pere Riera (1996), 'Is the Income Elasticity of Environmental Improvements Less than One?', Environmental and Resource Economics, 7, $45-55$. 
Markandya, A. (1998), 'Poverty, Income Distribution and Policy Making', Environmental and Resource Economics, 11(3-4), 459-72.

McGuire, Martin C. and Henry Aaron (1969), 'Efficiency and Equity in the Optimal Supply of a Public Good', Review of Economics and Statistics, 51(1), 31-9.

Metcalf, G.E. (1999), 'A Distributional Analysis of Green Tax Reforms', National Tax Journal, 52, 655-81.

Millimet, D. and D. Slottje (2000), 'The Distribution of Pollution in the US: An Environmental Gini Approach', mimeo, Department of Economics, Southern Methodist University, Dallas.

OECD (Organisation for Economic Cooperation and Development) (1994), The Distributive Effects of Economic Instruments for Environmental Policy, Paris: OECD.

OECD (1997), Evaluating Economic Instruments for Environmental Policy, Paris: OECD.

OECD (2003), Synthesis Report on Environment and Employment, OECD Monograph, ENV/EPOC/WPNEP(2003)11Final.

Olson, M. (1965), The Logic of Collective Action, Cambridge, MA: Harvard University Press.

Parry, I.W. (2004), 'Are Emissions Permits Regressive?', Journal of Environmental Economics and Management, 47, 364-87.

Poterba, J.M. (1991), 'Is the Gasoline Tax Regressive?', Tax Policy and the Economy, vol. 5, Cambridge, MA: National Bureau of Economic Research, pp. 145-64.

Ringquist, E. (1998), 'A Question of Justice: Equity in Environmental Litigation', Journal of Politics, 60(4), November, 1148-65.

Robison, H.D. (1985), 'Who Pays for Industrial Pollution Abatement?', Review of Economics and Statistics, 67(4), 702-6.

Shiell, Leslie (2003), 'Equity and Efficiency in International Markets for Pollution Permits', Journal of Environmental Economics and Management, 46, 38-51.

Shoup, Carl S. (1989), 'Rules for Distributing a Free Government Service among Areas of a City', National Tax Journal, 52(2), 103-21.

Sipes, K. and R. Mendelsohn (2001), 'The Effectiveness of Gasoline Taxation to Manage Air Pollution', Ecological Economics, 2(36), 299-309.

Smith, S. (1992), 'The Distributional Consequences of Taxes on Energy and the Carbon Content of Fuels', European Economy, Special Edition, 1, 241-68.

Symons, E., J. Proops and P. Gay (1994), 'Carbon Taxes, Consumer Demand, and Carbon Dioxide Emissions: A Simulation Analysis for the UK', Fiscal Studies, 15(2), 19-43.

Tiebout, C. (1956), 'A Pure Theory of Local Expenditures', Journal of Political Economy, LXIV, 416-24.

Walls, Margaret and Jean Hanson (1999), 'Distributional Aspects of an Environmental Tax Shift: The Case of Motor Vehicle Emissions Taxes', National Tax Journal, 52(1), 53-65.

West, Sarah and Roberton C. Williams III (2002), 'Estimates from a Consumer Demand System: Implications for the Incidence of Environmental Taxes', NBER Working Paper No. 9152. 
Nick Johnstone and Ysé Serret - 9781781951132 Downloaded from PubFactory at 04/26/2023 09:21:56AM via free access 